\title{
PENURUNAN KADAR LIMBAH LOGAM TIMBAL (PB) DENGAN METODE KHELASI MENGGUNAKAN BELIMBING WULUH (Averrhoa Bilimbi)
}

\author{
Yusbarina*), Marlianis \\ Program Pendidikan Kimia, Fakultas Tarbiyah dan Keguruan, \\ Universitas Islam Negeri Sultan Syarif Kasim Riau, Indonesia \\ *) Email: yusbarina_7@yahoo.com
}

\begin{abstract}
ABSTRAK
Logam-logam pada umumnya dapat membentuk ikatan dengan bahan-bahan organik alami maupun buatan melalui atom karbon, gugus karboksilat dan atom-atom yang mempunyai elektron bebas dalam senyawa organik sehingga membentuk kompleks koordinasi. Penelitian ini bertujuan untuk melihat pengaruh konsentrasi dan waktu pencampuran belimbing wuluh terhadap penurunan kadar limbah simulasi logam timbal $(\mathrm{Pb})$. Variasi konsentrasi belimbing wuluh yaitu 15\%, 30\%, dan 45\%. Variasi waktu pencampuran yaitu 30 menit dan 60 menit. Sampel limbah simulasi logam timbal $(\mathrm{Pb})$ dengan konsentrasi $10 \mathrm{ppm}$ dicampurkan dengan larutan belimbing wuluh 15\%, 30\%, dan 45\% selama 30 menit dan 60 menit dan dianalisa menggunakan AAS. Berdasarkan hasil penelitian didapatkan bahwa larutan belimbing wuluh dapat menurunkan kadar logam $\mathrm{Pb}$ yang terdapat dalam limbah simulasi. Dengan penurunan tertinggi yaitu $52,06 \%$ pada sampel yang dicampur dengan belimbing wuluh pada konsentrasi $45 \%$ dan pada waktu pencampuran 60 menit. Konsentrasi belimbing wuluh dan waktu pencampurannya mempengaruhi penurunan kadar logam $\mathrm{Pb}$ yang terdapat dalam limbah simulasi. Semakin tinggi konsentrasi belimbing wuluh dan semakin lama pencampurannya maka semakin besar penurunan kadar logam $\mathrm{Pb}$ dalam limbah simulasi.
\end{abstract}

Kata kunci : Logam $\mathrm{Pb}$, Belimbing wuluh, Khelasi

\section{PENDAHULUAN}

Timbal $(\mathrm{Pb})$ adalah logam berat yang dapat terakumulasi di dalam lingkungan, tidak dapat terurai secara biologis dan bersifat toksik. Toksisitas $\mathrm{Pb}$ dapat merusak organ tubuh dan menurunkan kecerdasan pada anak. Logam $\mathrm{Pb}$ dapat masuk ke dalam tubuh melalui makanan, minuman dan pernapasan. Sumber cemaran $\mathrm{Pb}$ di dalam makanan dapat berasal dari polusi udara, pencemaran tanah dan air. Dari beberapa penelitian, ditemukan adanya cemaran $\mathrm{Pb}$ di dalam berbagai sampel bahan makanan dengan berbagai level kontaminan.

Perkembangan industri yang begitu pesat di daerah Riau, menyebabkan kekhawatiran terhadap kualitas bahan makanan disekitar kita. Banyak penelitian yang meneliti tentang dampak pencemaran lingkungan terhadap bahan makanan. Salah satunya adalah penelitian yang dilakukan oleh Erlangga (2009). Dalam penelitiannya terbukti bahwa dalam air, sediman, dan organ ikan Baung (insang dan ginjal) tercemari logam berat $\mathrm{Pb}$ dan $\mathrm{Cd}$. Walaupun belum melampaui ambang batas, tetapi keberadaan logam ini dalam tubuh sangat berbahaya karena dapat menumpuk dalam tubuh dalam jangka waktu yang lama sebagai racun. Penelitian yang dilakukan oleh Sri Wulandari dkk (2009) memberikan informasi bahwa sungai siak telah tercemari oleh logam berat $\mathrm{Pb}$. 
Tercemarnya bahan makanan di sekitar kita menjadi kekhawatiran untuk mengkonsumsinya. Untuk itu perlu adanya pencegahan dan penjagaan agar makanan yang dikonsumsi aman dari logam berat. Hal ini sudah banyak yang melakukannya, diantaranya penelitian oleh Fitri Indah Sari dan S. keman (2010). Dari hasil penelitiannya, dengan menambahkan larutan asam cuka pada daging kerang biru maka kadar logam berat Kadmium (Cd) berkurang dari sebelumnya. Hal yang sama juga dilakukan oleh Dra. Fatimah Nisma. M.Si dan DR. Yusnidar Yusuf. M.Si yaitu dengan menambahkan air perasan jeruk nipis dalam kerang hijau untuk menurunkan kadar logam $\mathrm{Pb}, \mathrm{Cd}$, dan $\mathrm{Cu}$.

Upaya menurunkan kadar logam berat pada makanan banyak dilakukan dengan penambahan bahan organik (buatan dan alami). Pada penelitian ini, menggunakan bahan organik alami yaitu buah belimbing wuluh (Averrhoa bilimbi) yang secara tradisional telah digunakan oleh masyarakat sebagai bahan tambahan makanan dan obatobatan. Belimbing wuluh sangat mudah didapatkan, namun belum dimanfaatkan secara maksimal. Belimbing wuluh masih banyak terbuang begitu saja.

Bahan organik ini bertindak sebagai sekuestran yang dapat mengikat logam dalam bentuk ikatan kompleks sehingga dapat mengalahkan sifat dan pengaruh jelek logam tersebut dalam bahan makanan. Proses pengikatan logam merupakan proses keseimbangan pembentukan ion kompleks logam dengan sekuestran (senyawa pengkelat). Artinya proses ini dipengaruhi oleh konsentrasi senyawa yang ada. Secara umum keseimbangan ini dapat ditulis sebagai berikut:

$\mathrm{L}+\mathrm{S} \longrightarrow \mathrm{LS}$

Keterangan:

$$
\begin{aligned}
& \text { L = ion logam } \\
& \mathrm{S}=\text { sekuestran (ligan) } \\
& \text { LS = kompleks logam-sekuestran } \\
& \text { (Tri Marwati, 2005) }
\end{aligned}
$$

Banyak penelitian yang membuktikan bahwa konsentrasi suatu pengkelat mempengaruhi penurunan kadar logam berat. Diantaranya penelitian oleh Teguh Sastra Setiawan (2012) pada logam $\mathrm{Pb}$ dan $\mathrm{Cd}$ dalam udang dengan perendaman dengan jeruk nipis dan jeruk lemon dengan konsentrasi $50 \%$ dan $100 \%$ selama 30 menit. Dalam penelitian terjadi penurunan setelah perendaman dengan konsentrasi $50 \%$ dan $100 \%$. Kadar awal logam $\mathrm{Pb}$ dalam sampel 0,67 ppm, setelah perendaman dengan jeruk nipis $50 \%$ kadarnya 0,4 ppm dan pada perendaman dengan konsentrasi $100 \%$ kadarnya 0,35 ppm. Begitu juga dengan jeruk lemon, pada perendaman dengan konsentrasi $50 \%$ kadarnya $0,42 \mathrm{ppm}$ dan pada konsentrasi 100 ppm kadarnya 0,34 ppm.

Belimbing wuluh mengandung asam sitrat, yang mana asam sitrat ini termasuk ke dalam asam organik lemah. Asam sitrat termasuk zat pengikat logam yang merupakan zat penstabil dalam pengolahan bahan makanan. Asam sitrat mengikat logam dalam bentuk senyawa kompleks sehingga dapat mengalahkan sifat dan pengaruh jelek logam yang terdapat dalam bahan makanan.

Untuk melihat pengaruh konsentrasi dan waktu perendaman, maka digunakan limbah simulasi yang memiliki kadar logam Timbal $(\mathrm{Pb})$ yang tinggi sebagai sampel. Limbah simulasi merupakan limbah larutan yang dibuat di laboratorium dari larutan timbal $\left[\mathrm{Pb}\left(\mathrm{NO}_{3}\right)_{2}\right]$.

\section{METODOLOGI PENELITIAN}

\section{Alat}

Alat yang digunakan pada penelitian ini adalah peralatan gelas yang lazim digunakan 
di laboratorium penelitian kimia analitik, dan spektrofotometri serapan atom perkin elmer.

\section{Bahan}

Bahan yang digunakan pada penelitian ini adalah aquades, asam nitrat, $\mathrm{Pb}\left(\mathrm{NO}_{3}\right)_{2}$, larutan belimbing wuluh, dan limbah simulasi timbal $10 \mathrm{ppm}$.

\section{Prosedur Kerja}

\section{Pembuatan Limbah Simulasi Timbal (Pb)}

Limbah simulasi yang akan digunakan adalah limbah simulasi Timbal dengan konsentrasi 10 ppm.

a. Larutan Induk Timbal $1000 \mathrm{ppm}$

Ditimbang 1,598 gram $\mathrm{Pb}\left(\mathrm{NO}_{3}\right)_{2}$ kemudian dimasukkan ke dalam labu ukur $1000 \mathrm{ml}$ dan ditambah aquades sampai tanda batas.

b. Larutan limbah simulasi Timbal dengan konsentrasi $10 \mathrm{ppm}$

Diambil sebanyak $1 \mathrm{ml}$ larutan induk Timbal 1000 ppm dan dimasukkan kedalam labu ukur $100 \mathrm{ml}$. Kemudian ditambahkan dengan aquades sampai dengan tanda batas.

\section{Pembuatan ekstrak belimbing wuluh dengan berbagai konsentrasi}

Buah belimbing wuluh dicuci bersih. Kemudian dipotong kecil - kecil dan dimasukkan ke dalam juice extractor dan diekstrak tanpa penambahan air. Hasilnya disaring sebanyak dua kali.

a. Larutan ekstrak belimbing wuluh $15 \%$

$15 \mathrm{ml}$ ekstrak buah belimbing wuluh dimasukkan ke dalam labu ukur $100 \mathrm{~mL}$ dan ditambahkan dengan aquades sampai tanda batas dan dihomogenkan.

b. Larutan ekstrak belimbing wuluh $30 \%$

$30 \mathrm{ml}$ ekstrak buah belimbing wuluh dimasukkan ke dalam labu ukur $100 \mathrm{ml}$, kemudian ditambahkan dengan aquades sampai tanda batas dan dihomogenkan. c. Larutan belimbing wuluh $45 \%$

$45 \mathrm{ml}$ ekstrak buah belimbing wuluh dimasukkan ke dalam labu ukur $100 \mathrm{ml}$, kemudian ditambahkan dengan aquades sampai tanda batas dan dihomogenkan.

\section{Khelasi Logam Timbal (Pb) dengan Belimbing Wuluh}

Masing - masing sebanyak $20 \mathrm{~mL}$ sampel limbah simulasi logam Timbal $(\mathrm{Pb})$ dengan konsentrasi 10 ppm berturut berturut dicampurkan dengan larutan belimbing wuluh $15 \%$ selama 30 menit (sampel I), larutan belimbing wuluh $15 \%$ selama 60 menit (sampel II), larutan belimbing wuluh $30 \%$ selama 30 menit (sampel III), larutan belimbing wuluh $30 \%$ selama 60 menit (sampel IV), larutan belimbing wuluh $45 \%$ selama 30 menit (sampel V), larutan belimbing wuluh $45 \%$ selama 60 menit (sampel VI). Setiap 10 menit dilakukan pengadukan agar konsentrasi larutan belimbing wuluh merata. Kemudian diukur kadar logam Timbal $(\mathrm{Pb})$ dalam limbah simulasi dengan Spetrofotometer Serapan Atom (SSA).

Pengukuran kadar logam Timbal $(\mathbf{P b})$ di dalam Limbah Simulasi

Untuk mengukur konsentrasi logam Timbal $(\mathrm{Pb})$ di dalam limbah simulasi dilakukan dengan SSA dimana metode pengukurannya mengacu pada SNI 066989.8-2004.

\section{HASIL DAN PEMBAHASAN}

Pemilihan belimbing wuluh sebagai sekuestran dalam penelitian ini disebabkan belimbing wuluh sudah sejak lama digunakan oleh masyarakat sebagai bumbu masak dan mudah didapat. Serta belum dimanfaatkan secara maksimal. Belimbing wuluh banyak terbuang begitu saja, padahal belimbing ini 
dapat digunakan sebagai sekuestran yang mengikat logam berbahaya dalam makanan.

Belimbing wuluh yang digunakan adalah belimbing dengan tingkat kematangan yang cukup, tidak terlalu muda dan tidak terlalu tua (lihat pada gambar 1).

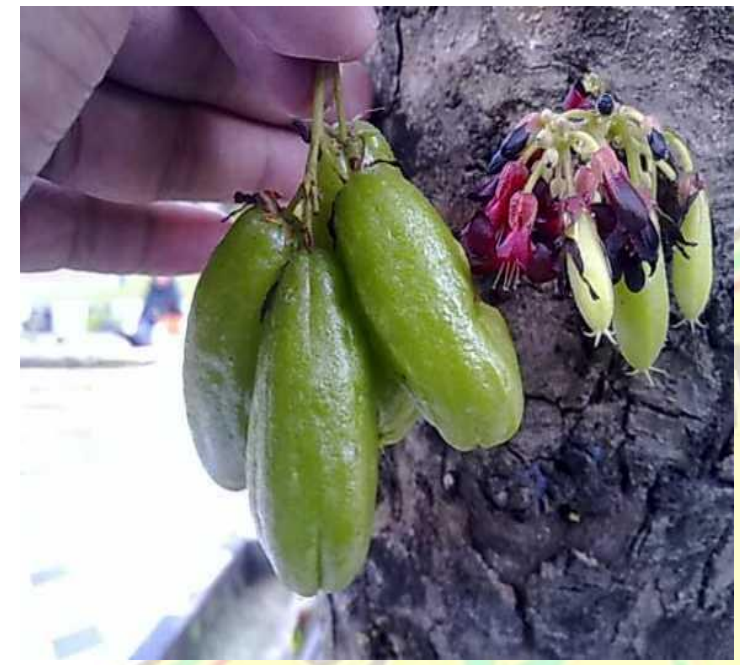

Gambar 1. Belimbing Wuluh (Averrhoa bilimbi)

Adapun kandungan dari buah belimbing wuluh adalah asam format, asam sitrat, asam askorbat (Vitamin C), saponin, tanin, glukosid, flavonoid, dan beberapa mineral terutama kalsium dan kalium dalam bentuk kalium sitrat dan kalsium oksalat. Rasa asam dari buah belimbing wuluh berasal dari senyawa asam yang terkandung dalamnya yaitu asam format, asam sitrat, dan asam askorbat.

Proses pembuatan ekstrak buah belimbing diawali dengan pencucian. Belimbing yang sudah dicuci dipotong kecil dan dimasukkan kedalam juice extractor tanpa menambahkan air. Air tidak digunakan karena kandungan air belimbing sudah cukup tinggi. Pengupasan juga tidak dilakukan karena kulit buah belimbing sangat tipis. Selanjutnya buah belimbing dihancurkan dengan juice extractor untuk diambil sarinya. Pada pembuatan ekstrak buah belimbing dilakukan penyaringan sebanyak dua kali yang bertujuan memisahkan sari buah dengan ampas yang terbawa pada saat penghancuran. Setelah di dapat ekstrak belimbing wuluh dilanjutkan dengan pembuatan ekstrak belimbing wuluh dengan konsentrasi $15 \%$, $30 \%$, dan $45 \%$.

Pemilihan tiga konsentrasi yaitu $15 \%$, $30 \%$, dan $45 \%$ agar dapat melihat seberapa besar pengaruh konsentrasi belimbing wuluh dalam penurunan kadar logam $\mathrm{Pb}$, dengan membandingkan penurunannya dalam setiap konsentrasi. Konsentrasi ini diambil karena tidak terlalu tinggi sehingga tidak terlalu asam. Jika terlalu asam, ini akan mempengaruhi cita rasa jika diaplikasikan ke dalam bahan makanan.

Nilai penurunan kadar logam berat $\mathrm{Pb}$ dalam limbah simulasi setelah diberi perlakuan pencampuran dengan perasan belimbing wuluh dengan konsentrasi $15 \%$, $30 \%, 45 \%$ dan waktu pencampuran 30 menit dan 60 menit dapat dilihat pada gambar di bawah ini:

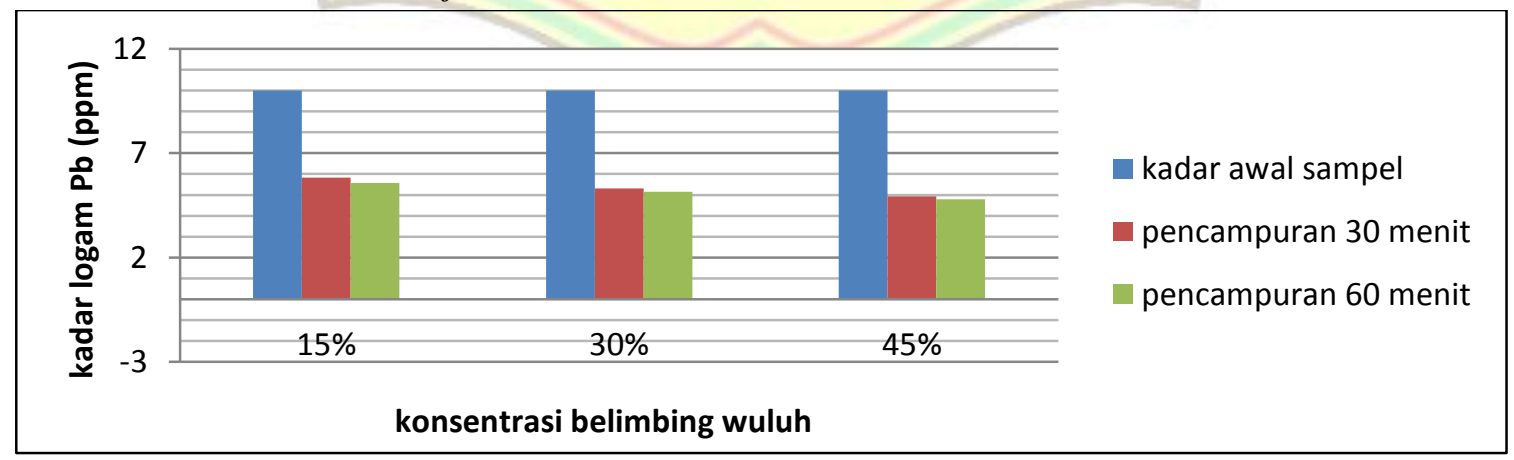

Gambar 2. Kadar Logam Pb dalam sampel setelah khelasi dengan belimbing wuluh 
Gambar 2 di atas menunjukkan bahwa pencampuran limbah simulasi dengan belimbing wuluh dengan konsentrasi $15 \%$, $30 \%$, dan $45 \%$ pada waktu 30 menit dan 60 menit mampu menurunkan kadar logam $\mathrm{Pb}$ dalam limbah simulasi masing- masing berturut-turut 5,8334 ppm (sampel I), 5,5750 ppm (sampel II), 5,3167 ppm (sampel III), 5,1479 ppm (sampel IV), 4,9271 ppm (sampel V), 4,7938 ppm (sampel VI). Penurunan kadar logam $\mathrm{Pb}$ ini dapat kita ketahui setelah membandingkan kadar logam $\mathrm{Pb}$ sebelum pencampuran dengan belimbing wuluh dengan kadar logam $\mathrm{Pb}$ setelah pencampuran dengan belimbing wuluh. Data lengkap dapat dilihat pada tabel 1 berikut ini

Tabel 1. Penurunan Kadar Logam $\mathrm{Pb}$ dalam sampel

\begin{tabular}{|c|l|c|c|c|}
\hline No & \multicolumn{1}{|c|}{ Sampel } & $\begin{array}{c}\text { Kadar Pb sebelum } \\
\text { pencampuran } \\
(\mathbf{p p m})\end{array}$ & $\begin{array}{c}\text { Kadar Pb setelah } \\
\text { pencampuran (ppm) }\end{array}$ & $\begin{array}{c}\text { \% penurunan kadar } \\
\text { Pb (ppm) }\end{array}$ \\
\hline 1 & Sampel I & 10 & 5,8334 & $41,67 \%$ \\
\hline 2 & Sampel II & 10 & 5,5750 & $44,25 \%$ \\
\hline 3 & Sampel II & 10 & 5,3167 & $46,83 \%$ \\
\hline 4 & Sampel IV & 10 & 5,1479 & $48,52 \%$ \\
\hline 5 & Sampel V & 10 & 4,9271 & $50,73 \%$ \\
\hline 6 & Sampel VI & 10 & 4,7938 & $52,06 \%$ \\
\hline
\end{tabular}

Tabel 1 di atas menunjukkan keefektifan metode khelasi menggunakan belimbing wuluh dalam menurunkan kadar logam $\mathrm{Pb}$. Penurunan kadar logam Timbal $(\mathrm{Pb})$ dengan metode khelasi ini sudah melebihi $50 \%$.

Yang berperan sebagai pengkelat dalam belimbing wuluh ini adalah asam sitrat. Hal ini dikarenakan logam berat berikatan dengan atom yang memiliki ion bebas, sedangkan asam sitrat memiliki empat elektron bebas pada komplek (pengikat logam). Terjadinya reaksi antara zat pengikat logam dengan ion logam melalui ikatan koordinasi menyebabkan ion logam kehilangan sifat ionnya dan mengakibatkan logam berat tersebut kehilangan sebagian besar toksisitasnya.

Asam sitrat mempunyai 4 pasang elektron bebas pada molekulnya yaitu pada gugus karboksilat yang dapat diberikan pada ion logam sehingga menyebabkan terbentuknya ion kompleks yang dengan

mudah larut dalam air (Teguh S, 2012). Struktur asam sitrat dapat dilihat di bawah ini:<smiles>O=C(O)CC(O)(CC(=O)O)C(=O)O</smiles>

Gambar 3. Struktur Asam Sitrat

Keasaman asam sitrat didapatkan dari tiga gugus karboksil $\mathrm{COOH}$ yang dapat melepas proton dalam larutan. Jika hal ini terjadi, ion yang dihasilkan adalah ion sitrat. Sitrat sangat baik digunakan dalam larutan penyangga untuk mengendalikan $\mathrm{pH}$ larutan. Ion sitrat dapat bereaksi dengan banyak ion logam membentuk garam sitrat. Selain itu, sitrat dapat mengikat ion-ion logam dengan pengkelatan.

Logam-logam pada umumnya dapat membentuk ikatan dengan bahan-bahan organik alam maupun bahan-bahan organik buatan. Proses pembentukan ikatan tersebut 
dapat terjadi melalui pembentukan garam organik dengan gugus karboksilat seperti misalnya asam sitrat, tartarat, dan lain-lain.

Di samping itu, logam dapat berikatan dengan atom-atom yang mempunyai elektron bebas dalam senyawa organik sehingga terbentuk kompleks (Palar.
Selanjutya dilakukan uji statistik anova dua arah untuk mengetahui pengaruh konsentrasi dan waktu pencampuran belimbing wuluh terhadap penurunan kadar logam $\mathrm{Pb}$ dalam sampel. Hasil uji anova dua arah dapat dilihat pada tabel 2 di bawah ini:

H, 2004).

Tabel 2.

Tabel Ringkasan Anova dari Pengaruh Konsentrasi Belimbing Wuluh terhadap Penurunan Kadar Logam $\mathrm{Pb}$

\begin{tabular}{|l|c|c|c|c|c|c|}
\hline \multirow{2}{*}{ Jumlah Variasi } & \multirow{2}{*}{$\mathbf{d k}$} & Jumlah kuadrat & Rata-Rata Kuadrat & \multirow{2}{|c|}{ Fubel $_{\text {tatung }}$} & $\mathbf{1 \%}$ & $\mathbf{5 \%}$ \\
\hline Antar kelompok & 2 & 2,1457 & 1,0729 & 4433,4711 & 6,93 & 3,86 \\
Dalam kelompok & 12 & 0,0029 & 0,000242 & & & \\
\hline Total & 14 & 2,1486 & & & & \\
\hline
\end{tabular}

Berdasarkan hasil data di atas Fhitung lebih besar dari Ftabel baik pada taraf signifikan $1 \%$ maupun $5 \%$, sehingga $\mathrm{Ha}$ diterima dan $\mathrm{HO}$ ditolak. Ini berarti bahwa konsentrasi belimbing wuluh mempengaruhi penurunan kadar logam $\mathrm{Pb}$ dalam sampel. Dengan diterimanya Ha perlu dilakukan uji pasca Anova untuk melihat konsentrasi mana yang berbeda atau yang baik yang mempengaruhi penurunan kadar logam $\mathrm{Pb}$. Hasilnya diketahui bahwa konsentrasi yang baik dalam menurunkan kadar logam $\mathrm{Pb}$ adalah konsentrasi $45 \%$.

$$
\text { Yang menyebabkan semakin }
$$
menurunnya kadar logam $\mathrm{Pb}$ oleh kenaikan konsentrasi adalah kandungan asam sitratnya. Kita ketahui bahwa asam sitratlah yang bertindak sebagai pengkelat logam $\mathrm{Pb}$. Jika semakin tinggi konsentrasi belimbing wuluh maka kandungan asam sitratnya akan semakin banyak dan semakin banyak pula logam berat $\mathrm{Pb}$ yang terikat

Tabel 3.

Tabel Ringkasan Anova dari Pengaruh Waktu Pencampuran Belimbing Wuluh terhadap Penurunan Kadar Logam $\mathrm{Pb}$

\begin{tabular}{|l|c|c|c|c|c|c|}
\hline \multirow{2}{*}{ Jumlah Variasi } & \multirow{2}{*}{$\mathbf{d k}$} & Jumlah kuadrat & Rata-Rata Kuadrat & & \multicolumn{2}{|c|}{ F $_{\text {tabel }}$} \\
\cline { 5 - 7 } & & 0,157 & 0,157 & 648,7603 & 9,33 & 4,75 \\
Antar kelompok & 1 & 0,0029 & 0,000242 & & & \\
Dalam kelompok & 12 & 0,1599 & & & & \\
\hline Total & 13 & & & \\
\hline
\end{tabular}

Dari data tabel 3 di atas terlihat bahwa terjadi perbedaan yang signifikan antara Fhitung dengan Ftabel baik pada taraf $1 \%$ maupun pada taraf 5\%. Apabila Fhitung lebih besar dari Ftabel maka Ha diterima dan H0 ditolak. Dengan diterimanya $\mathrm{Ha}$ berarti adanya pengaruh yang diberikan oleh lamanya waktu pencampuran terhadap penurunan kadar logam $\mathrm{Pb}$ dalam sampel. Selanjutnya dilakukan uji pasca Anova untuk melihat perbedaan antara waktu pencampuran. Dan hasilnya bahwa waktu pencampuran yang mempunyai perbedaan dan yang baik dalam menurunkan kadar 
logam $\mathrm{Pb}$ adalah waktu pencampuran 60 menit.

Hal ini dikarenakan, semakin lama waktu pencampuran atau perendaman maka logam berat $\mathrm{Pb}$ akan semakin banyak terikat oleh pengkelatnya. Karena dengan semakin lamanya waktu pencampuran ini, kesempatan pengkelat semakin besar untuk mengikat logam berat $\mathrm{Pb}$.

\section{KESIMPULAN}

Berdasarkan hasil penelitian didapatkan bahwa larutan belimbing wuluh dapat menurunkan kadar logam $\mathrm{Pb}$ yang terdapat dalam limbah simulasi. Dengan penurunan tertinggi yaitu $52,06 \%$ pada sampel yang dicampur dengan belimbing wuluh pada konsentrasi $45 \%$ dan pada waktu pencampuran 60 menit. Konsentrasi belimbing wuluh dan waktu pencampurannya mempengaruhi penurunan kadar logam $\mathrm{Pb}$ yang terdapat dalam limbah simulasi. Semakin tinggi konsentrasi belimbing wuluh dan semakin lama pencampurannya maka semakin besar penurunan kadar logam $\mathrm{Pb}$ dalam limbah simulasi.

\section{DAFTAR PUSTAKA}

Aditya Rahman.2006. Kandungan Logam Berat Timbal $(\mathrm{Pb})$ dan Kadmium $(\mathrm{Cd})$ pada Beberapa Jenis Krustasea Di Pantai Batakan dan Takisung Kabupaten Tanah Laut Kalimantan Selatan. Bioscientiae. Vol.3, No.2

Ahmad, Rukaesih. 2004. Kimia Lingkungan. Yokyakarta: ANDI

Anis Nuraini, Lilis Sulistyorini. 2006. Perbandingan Penurunan Kadar $\mathrm{Pb}$ pada Kupang Awung (Mytilus viridis) dengan Menggunakan Perendaman Asam Asetat 25\% dan Aqua. Jurnal Kesehatan Lingkungan Vol.2, No.2
Annisa Fillaeli. (tanpa tahun). Cemaran Logam $\mathrm{Pb}$ dalam Makanan. Jurusan Pendidikan kimia FMIPA Universitas Negeri Yogyakarta

Anonim. Asam sitrat. http://id.wikipedia.org/wiki/Asam_sitrat , 9/11/2012

Anonim, Bahan Pengikat Logam pada Makanan, http://sienvisgirl.wordpres.com/2011/05 /30/bahan-pengikat-logam-padamakanan-sekuestran/ 9/11/2012

Darmono. 1995. Logam dalam Sistem Biologi Makhluk Hidup. Jakarta: UI Press

Dewi Nugraha Wati, dkk. 2009. Pemanfaatan Buah Belimbing Wuluh (Averrhoa bilimbi) Sebagai Cairan Akumulator Secara Alami dan Ramah Lingkungan.

http://dewinugrahawati.blog.uns.ac.id/fi les/2010/05/document.pdf. 29/01/2013

Erlangga. 2007. Efek Pencemaran Perairan Sungai Kampar di Provinsi Riau terhadap Ikan Baung (Hemibagrus nemurus). Skripsi. Bogor: Sekolah Pasca Sarjana Institut Pertanian Bogor

Fitri Indah Sari dan S. keman. 2005. Efektifitas Larutan Asam Cuka untuk Menurunkan Kandungan Logam Berat Cadmium dalam Daging Kerang Bulu. Jurnal Kesehatan Lingkungan, Vol.1, No. 2

Lingga, Pinus. 2000. Bertanam Belimbing. Jakarta: Penebar Swadaya

Palar, H. 2004. Pencemaran \& Toksikologi Logam Berat. Jakarta: Penerbit RinekanCipta

Sri Wulandari. 2005. Identifikasi Bakteri Pengikat Timbal $(\mathrm{Pb})$ pada Sedimen di Perairan Sungai Siak. Jurnal Biogenesis Vol. 1(2):62-65 
Sudijono, Anas. 2008. Pengantar Statistik Pendidikan. Jakarta: PT RajaGrafindo Persada

Supriyanto C, et al. 2007. Analisis Cemaran Logam Berat $\mathrm{Pb}, \mathrm{Cu}$, dan Cd Pada Ikan Air Tawar dengan Metode Spektrometri Nyala Serapan Atom (SSA). Jurnal Seminar Nasional III SDM Teknologi Nuklir Yogyakarta

Tarzan Purnomo, Muchyiddin.2007. Analisis Kandungan Timbal $(\mathrm{Pb})$ pada Ikan Bandeng (Chanos chanos Forsk.) di Tambak Kecamatan Gresik. Neptunus, Vol. 14, No. 1

Teguh Sastra Setiawan. 2012. The Effectiveness of Various Types of Orange (Citrus Sp.) to the Reduction of $\mathrm{Pb}$ (Lead) and $\mathrm{Cd}$ (Cadmium) Heavy Metals Concentration on White Shrimp (Panaeus Marguiensis), LenteraBio Vol.1 No.1

Tri Marwati, et al. 2005. Pemucatan Minyak Daun Cengkeh dengan Metode Khelasi menggunakan Asam sitrat. Jurnal Teknologi Industri Pertanian Vol 17(2)

Yongki Kastanya Luthana. Asam Sitrat. http://www.scribd.com/doc/24470723/
Asam-SITRAT. 29/01/2013

Samsuri., M. Gozan., R. Mardius., M. Baiquni., H. Hermansyah., A. Wijanarko., B. Prasetya dan Nasikin. 2007. Pemanfaatan Selulosa Bagas untuk Produksi Ethanol Melalui Sakarifikasi dan Fermentasi Serentak dengan Enzim Xylanase. Jurnal Makara Teknologi. 11(1). Hlm 17-24.

Sumarmi. 2006. Botani dan Tinjauan Gizi Jamur Tiram Putih. Jurnal Inovasi Pertanian4(2). Hlm 124-130.

Suriawiria, Unus. 2001. Sukses Beragrobisnis Jamur Kayu. Jakarta.. 2002. Budidaya Jamur Tiram. Yogyakarta: Kanisius.

Tjitrosoepomo, G. 2010. Taksonomi Tumbuham Obat-Obatan. Yogyakarta: Gadjah Mada University Press.

Wiardani, I. 2010. Budidaya jamur Konsumsi. Yogyakarta: Lili publisher.

Winarni,I dan U. Rahayu. 2002. Pengaruh Formulasi Media Tanam dengan Bahan Dasar Serbuk Gergaji terhadap Produksi Jamur Tiram Putih (Peurotus ostreatus).Jurnal Matematika, Sain dan Teknologi. 3(2). Hlm 20-27. 